\title{
LA ADOPCIÓN DE ACUERDOS POR LAS CÁMARAS
}

\author{
Piedad García-Escudero MárqueZ \\ Departamento de Derecho Constitucional \\ Facultad de Derecho \\ Universidad Complutense de Madrid \\ piedadga@pdi.ucm.es
}

\begin{abstract}
RESUMEN
El artículo estudia la regulación constitucional y la práctica sobre la adopción de acuerdos por las Cámaras que componen las Cortes Generales, los diferentes tipos de quorum y de votación, así como la problemática que plantea la indelegabilidad del voto establecida por el art. 79.3 CE y las soluciones dadas en la normativa y realidad parlamentaria a las necesidades de sustitución temporal de parlamentarios.

Palabras clave: Parlamento, Derecho parlamentario, adopción de acuerdos, voto, voto electrónico, delegabilidad del voto parlamentario, sustitución temporal de parlamentarios.
\end{abstract}

\section{ABSTRACT}

This article looks into the constitutional regulation and practice of adopting resolutions by both the Houses of Parliament, the different types of quorum and voting rates, as well as the fact that the vote cannot be delegated as established by article 79.3 CE and the answers provided by law and facts regarding the need for a temporary replacement of MPs.

Keywords: Parliament, Parliamentary law, adoption of resolutions, vote, e-vote, delegation of vote in Parliament, temporary replacement of MPs.

\section{ZUSSAMENFASSUNG}

Der Artikel untersucht die verfassungsrechtliche Regulierung und die Praxis der Beschlussfassung durch die Kammern, welche das Spanische Parlament konstituieren, ferner die verschiedenen Arten des Quorum und der Wablabstimmung, ebenso die Problematik, welche daraus resultiert, dass das Stimmrecht laut Artikel 79.3 der Spanischen Verfassung nicht übertragbar ist sowie die vorliegenden gesetzlich verankerten und in der parlamentarischen Realität angewandten Lösungen im Falle des zeitlich befristeten Ersatzes von Parlamentariern.

Schlüsselwörter: Parlament, Parlamentsrecht, Beschlussfassung, Wahl, elektronische Stimmabgabe, Delegierbarkeit der parlamentarischen Wahlstimme, befristeter Ersatz von Parlamentariern 
SUMARIO: I. INTRODUCCIÓN.-II. REGULACIÓN DE LA ADOPCIÓN DE ACUERDOS POR LAS CÁMARAS.-1. Quorum y mayorías parlamentarias.-2. Convocatoria reglamentaria.-3. Quorum de constitución y quorum para adoptar acuerdos.-4. Mayorías necesarias para la adopción de acuerdos.-4.1. Clases de mayorías.-4.2. Regla general: mayoría simple. Formas de votación.-4.3. Mayorías especiales.-5. Jurisprudencia constitucional sobre voto electrónico.-III. EL VOTO PERSONAL E INDELEGABLE.-1. Evolución y sistemas en Derecho comparado.-1.1. Pairing.-1.2. Voto por delegación.-1.3. Sustitución temporal de parlamentarios.-1.4. Voto a distancia.-2. Derecho histórico.-3. Parlamentos autonómicos.-4. Voto telemático en el Congreso de los Diputados y en el Senado.-5. Otras cuestiones relacionadas con la indelegabilidad del voto.-IV. A MODO DE CONCLUSIÓN.

\section{INTRODUCCIÓN}

El Parlamento es un órgano deliberante que, mediante la discusión, pretende alcanzar la verdad relativa, o al menos lo pretendía en el modelo clásico, antes de que la partitocracia y la consiguiente disciplina de grupo entraran en juego y transformaran la institución en una máquina de votar en la que prima la voluntad sobre la razón. En efecto, la voluntad, como ocurre en general en los órganos colegiados, se articula en las asambleas mediante la votación. Deliberación y votación ocupan las sesiones parlamentarias; como señalara Bentham ${ }^{1}$, debatir y votar son dos operaciones distintas y no ha de comenzar la última sino después de finalizada la primera, para impedir las decisiones erróneas por falta de conocimiento, pero también las decisiones contrarias a la voluntad de la asamblea ${ }^{2}$. La libertad de una asamblea — afirma este autor - reside en la expresión de su voluntad, siendo necesario que cada uno pueda dar su voto con arreglo a su verdadero deseo y que haya seguridad en el resultado de haber conseguido la voluntad general.

En consecuencia, entre las normas que regulan el funcionamiento de las asambleas parlamentarias ofrecen particular importancia las relativas a la adopción de acuerdos, que establecen el procedimiento mediante el cual

1 J. Bentham, Tácticas parlamentarias, Madrid, Congreso de los Diputados, 1991,

${ }^{2}$ Recuerda Bentham lo absurdo de que, frente a la firme práctica inglesa del orden sucesivo de las operaciones de debatir y votar, en las primeras actuaciones de los Estados Generales de 1789 se llamaba a los miembros a controvertir y votar al mismo tiempo, lo que llevaba entre otras cosas a confusiones en el lenguaje: parecer, opinión, voto, deliberación, se ofrecían como sinónimos en todos los acuerdos, situación que califica de caos perpetuo. Vid. ibid., p. 188. 
la voluntad de una mayoría de la Cámara puede atribuirse a la misma. De su relieve da idea que sean de las pocas reglas de funcionamiento incorporadas al título III de la Constitución de 1978. Dedicamos este trabajo al examen de estas normas constitucionales, así como a su desarrollo en los Reglamentos del Congreso y del Senado, y a las novedades introducidas en los últimos tiempos, que en el periodo constituyente no podían preverse.

\section{REGULACIÓN DE LA ADOPCIÓN DE ACUERDOS POR LAS CÁMARAS}

\section{Quorum y mayorías parlamentarias}

Los dos primeros apartados del art. 79 de la Constitución ${ }^{3}$ regulan aspectos relacionados con la adopción de acuerdos por las Cámaras, fijando requisitos de quorum y mayorías para que aquellos sean válidos. Como señalara Tosi ${ }^{4}$, la expresión del voto es la única manifestación jurídicamente válida de la voluntad y la regulación de las votaciones está íntimamente relacionada con la validez de los acuerdos, dado el principio general del Derecho que imputa al colegio entero la decisión válidamente adoptada por la mayoría de sus miembros.

Podemos distinguir tres tipos de quorum o número de miembros de un órgano colectivo necesario para la validez de sus reuniones o acuerdos: a) quorum de presencia o de constitución: número de miembros necesario para que el órgano se entienda válidamente constituido; b) quorum de acuerdos o de votación: número de miembros presentes necesario para que el órgano pueda adoptar acuerdos; c) quorum de aprobación o mayoría: número de votos necesario para que un acuerdo se entienda adoptado.

$\mathrm{El}$ art. 79 no establece ningún quorum de presencia, esto es, un número de miembros para que las Cámaras puedan iniciar o celebrar sus reuniones ${ }^{5}$. Sí para adoptar acuerdos, es decir, para la celebración de votaciones,

${ }^{3}$ Que proceden del texto del Anteproyecto de Constitución, solo modificado su apartado 2 en la Comisión Constitucional del Congreso para incluir la palabra «especiales» y precisar que los reglamentos pueden establecer estas mayorías «para elección de personas».

${ }^{4}$ S. Tosi, Dirito parlamentare, Milano, Giufrè, 1993, p. 248.

5 Sobre el fundamento y los escasos ejemplos comparados de exigencia de quorum de presencia — que es muy bajo en la Cámara de los Comunes (cuarenta miembros) y el propio Bentham, Tácticas parlamentarias, op. cit., p. 262, recordaba que a menudo no se hallaba presente ese número- vid. E. RECODER DE CASSO, «Artículo 79», en F. GarRIDo Falla (dir.), Comentarios a la Constitución, 3. ${ }^{a}$ ed., Madrid, Civitas, 2001, pp. 1321 y ss. 
siendo necesaria la presencia de la mayoría de sus miembros ${ }^{6}$ (cuya forma de cómputo tendremos ocasión de precisar más adelante).

Asimismo, se establece el quorum ordinario de aprobación de acuerdos, fijado en la mayoría [simple, añaden los arts. 79.1 del Reglamento del Congreso (en adelante, RC) y 93.1 del Reglamento del Senado (en adelante, RS)] de los miembros presentes (más votos síes que noes, siendo indiferente el número de abstenciones ${ }^{7}$, siempre que se cumpla con el quorum de presencia anteriormente expuesto), sin perjuicio de las mayorías especiales establecidas por la Constitución, las leyes orgánicas o los Reglamentos de las Cámaras para la elección de personas.

Con carácter previo, el art. 79.1 CE exige para la adopción válida de acuerdos que las Cámaras estén reunidas reglamentariamente (una cautela para evitar las asambleas de parlamentarios que refuerza la declaración del art. 67.3$)^{8}$, lo que nos lleva a examinar en primer lugar los requisitos de convocatoria y constitución del Pleno y de las comisiones — aunque el artículo solo se refiera al primero de estos órganos- que establecen los Reglamentos del Congreso de los Diputados y del Senado.

\section{Convocatoria reglamentaria}

Del Reglamento del Congreso se desprende que el Pleno y las comisiones de esta Cámara no podrán reunirse sin que se hayan cumplido los siguientes requisitos: a) convocatoria y constitución del Pleno por el presidente, por propia iniciativa o a solicitud, al menos, de dos grupos parlamentarios o de una quinta parte de los miembros de la Cámara (art. 54 $\mathrm{RC}$ ), y convocatoria de las comisiones por el presidente de la Cámara o de

\footnotetext{
${ }^{6}$ Se siguen así los precedentes de nuestras Constituciones históricas, las cuales exigen que para las votaciones estén presentes la mitad más uno de los diputados: que deben componer las Cortes en 1812 (art. 139); que componen cada cuerpo colegislador en las Constituciones de 1837 (art. 38), 1845 (art. 37) y 1876 (art. 43). La de 1869 (art. 51) especifica más el número sobre el que ha de computarse el quorum: el número total de los individuos que tengan aprobadas sus actas, esto es, el número de componentes de la Cámara en el momento de la votación, que es la práctica seguida para el cómputo también en nuestras actuales Cámaras, al menos desde 1978.

${ }^{7}$ De acuerdo también con la práctica, se computa así la mayoría de presentes, sin tener en cuenta las abstenciones, en una interpretación que no es literal de la Constitución ni las normas reglamentarias y que desarrollaremos en el epígrafe 3.

${ }^{8}$ Conforme al cual las reuniones de parlamentarios que se celebren sin convocatoria reglamentaria no vincularán a las Cámaras y no podrán ejercer sus funciones ni ostentar sus privilegios.
} 
la comisión, a iniciativa propia o a petición de dos grupos parlamentarios o de una quinta parte de los miembros de la comisión (art. $42 \mathrm{RC)}$; b) fijación del orden del día: por el presidente, de acuerdo con la Junta de Portavoces, para las sesiones plenarias (art. 67.1 RC), y por la Mesa de la comisión, de acuerdo con el presidente de la Cámara y teniendo en cuenta el calendario fijado por la Mesa del Congreso, para las sesiones de comisiones (art. 67.2 RC) ${ }^{9}$; c) distribución a los diputados con derecho a participar en la sesión del informe, dictamen o documentación que haya de servir de base en el debate (art. $69 \mathrm{RC}$ ), y d) transcurso de un plazo de cuarenta y ocho horas, al menos, desde la distribución antedicha, salvo acuerdo de la Mesa del Congreso o de la comisión, debidamente justificado (art. 69 RC).

El Reglamento del Senado diferencia entre las sesiones del Pleno y de las comisiones. Convoca el Pleno su presidente (art. 37.2 RS), con un orden del día que fija de acuerdo con la Mesa, oída la Junta de Portavoces (art. 71 RS). Desde el mismo día de la convocatoria del Pleno para aprobación de textos legislativos (art. 119 RS), quedarán en la Secretaría de la Cámara, a disposición de los senadores, los dictámenes de las comisiones y los votos particulares que hayan de ser sometidos al Pleno, sin perjuicio de su impresión y distribución.

En cuanto a las comisiones, estas son convocadas, asimismo, por su presidente o el de la Cámara, directamente o a petición de un tercio de sus miembros (la Comisión General de las Comunidades Autónomas también a petición del Gobierno o de un Consejo de Gobierno de Comunidad Autónoma, art. 56 bis 3 RS), con una antelación mínima de tres días, salvo casos de urgencia (art. 61.1 y 2 RS) ${ }^{10}$. También en esta Cámara puede su presidente armonizar y ordenar las convocatorias de las comisiones en consideración a las exigencias del trabajo del Senado (art. 61.3 RS). El orden del día es fijado por el presidente de la comisión, oída la Mesa respectiva y teniendo en cuenta en su caso el programa de trabajo de la Cáma-

${ }^{9}$ Conforme al art. $67.4 \mathrm{RC}$, a iniciativa de un grupo parlamentario o del Gobierno, la Junta de Portavoces podrá acordar, por razones de urgencia y unanimidad, la inclusión en el orden del día de un determinado asunto, aunque no hubiere cumplido todavía los trámites reglamentarios.

${ }^{10}$ A diferencia del Senado, no se establece una antelación mínima para la convocatoria de las comisiones (ni del Pleno) en el Reglamento del Congreso, pero esta ausencia se ve atemperada por la exigencia en el art. 69 de la distribución de la documentación base del debate con al menos cuarenta y ocho horas de antelación, salvo acuerdo en contrario de la Mesa del Congreso o de la comisión, debidamente justificado. En aplicación de este precepto, las comisiones (y el Pleno) suelen convocarse con cuarenta y ocho horas de antelación, excepto en casos de urgencia. 
ra; un tercio de los miembros de la comisión puede incluir un solo asunto con carácter prioritario. El presidente del Senado puede convocar a las comisiones, fijando su orden del día, cuando lo haga necesario el desarrollo de los trabajos legislativos de la Cámara (art. 71.3 RS).

La convocatoria habrá de hacerse para uno de los días de la semana que el Reglamento considera hábiles para la reunión: de martes a viernes, en el Congreso (art. 62 RC), salvo acuerdo de celebración de sesión en otros días adoptado por el Pleno o la comisión, a iniciativa del presidente, dos grupos parlamentarios o una quinta parte de los miembros de la Cámara o de la comisión, o por la Mesa del Congreso, aceptado por la Junta de Portavoces ${ }^{11}$. En el Senado, las sesiones plenarias se celebran de martes a jueves, salvo que la misma Cámara acuerde que tengan lugar en otros días, a propuesta de su presidente, de la Junta de Portavoces o de cincuenta senadores (art. $76 \mathrm{RS}$ ), siendo necesario el mismo acuerdo para prolongar las sesiones más de cinco horas (art. 67 RS). Las comisiones podrán reunirse de lunes a viernes (art. 79 RS), salvo que la comisión, a propuesta de su presidente o de cinco miembros, acuerde que se celebre en otros días de la semana (art. art. $78 \mathrm{RS})^{12}$.

Lo hasta aquí expuesto se refiere a las reuniones en periodos ordinarios de sesiones. Tanto el Pleno como las comisiones pueden celebrar sesiones extraordinarias fuera de los periodos ordinarios que determina el art. 73.1 CE (septiembre a diciembre y febrero a junio), siendo precisa petición del Gobierno, de la Diputación Permanente o de la mayoría absoluta de los miembros de la Cámara. La petición ha de contener el orden del día que se propone, para el cual se convoca la sesión (en el plazo de diez días en el Senado, art. 70.2 RS), que no podrá levantarse hasta agotar aquel (arts. 61.3 RC y 70.2 RS). Convoca las sesiones extraordinarias el presidente de la Cámara.

Se ha instaurado en nuestras Cámaras la limitación de sesiones simultáneas de un número de comisiones por acuerdo de la Mesa en cada legislatura. En un principio se alegaba como causa el número limitado de taquígrafos, a efectos de reproducción de la sesión en el Diario

${ }^{11}$ Las razones originarias de esta limitación provenían del deseo de reservar días al trabajo del parlamentario en su circunscripción, así como a las dificultades y duración de los desplazamientos, aunque los Reglamentos históricos permitían las sesiones ordinarias todos los días no festivos salvo «los días y cumpleaños del rey y del inmediato sucesor a la Corona, y los de fiesta nacional salvo razones de urgencia». Es el Reglamento de 1918 el primero que excluye también los lunes (art. 95).

${ }^{12}$ Una habilitación general de días se acuerda para la tramitación del Proyecto de Ley de Presupuestos Generales del Estado. 
de Sesiones, e incluso de salas de reunión, pero, en realidad, responde a las dificultades que la coincidencia plantea a los grupos parlamentarios de menor tamaño, circunstancia que también ha llevado en el Senado a acuerdos de prohibición de reunión de comisiones los martes por la mañana para no coincidir con las reuniones de Mesa y Junta de Portavoces, así como de los grupos.

En ambas Cámaras, las sesiones de las comisiones y las del Pleno no pueden celebrarse de forma simultánea ${ }^{13}$. No lo dice el Reglamento del Congreso, pero así se ha aplicado estrictamente ${ }^{14}$, incluso para las reuniones de ponencia y de Mesas de comisión de convocatoria formal. El art. 79 RS lo impone tajantemente: «En ningún caso (las comisiones) podrán simultanear sus sesiones con las del Pleno».

En cuanto a las horas de reunión, el art. 77 RS prevé que las sesiones tengan una duración máxima de cinco horas, a menos que la Cámara (a propuesta de su presidente, de la Junta de Portavoces o de cincuenta diputados) o la comisión (a propuesta de su presidente o cinco de sus miembros) (art. $78 \mathrm{RS}$ ), decidan lo contrario, acuerdo que a veces se olvida adoptar en el fragor del debate.

\section{Quorum de constitución y quorum para adoptar acuerdos}

En concordancia con la falta de previsión constitucional, el Reglamento del Senado declara expresamente que no se precisa un quorum para la constitución de sus órganos, manteniendo el art. 82 RS la regla del art. 68 del Reglamento provisional de esta Cámara, según la cual «tanto el Pleno como las comisiones, debidamente convocadas, abrirán sus sesiones cualquiera que sea el número de senadores presentes, sin perjuicio de lo que en

13 Esta es la regla general en Derecho comparado, salvo en los países anglosajones, el Benelux y algunos nórdicos. En otros ordenamientos, la incompatibilidad puede ser salvada en casos excepcionales (Francia y Portugal) o por autorización del presidente del Parlamento (Alemania e Italia). En el Parlamento británico, la comisión para la modernización de la Cámara de los Comunes (A reform programme, Second Report, publicado el 5 de septiembre de 2002) recomendó, pese a fijar horas límite a las sesiones para que los miembros del Parlamento puedan atender a sus circunscripciones, que las comisiones y el Pleno no coincidan durante el question time ni con otros asuntos.

${ }^{14}$ La práctica inveterada se rompió, con la consecuencia de que ello pueda ser alegado como precedente, con la celebración simultánea de sesiones plenarias y de la Comisión Constitucional para dictaminar la propuesta de reforma del Estatuto de Autonomía de Cataluña (vid. Diario de Sesiones del Pleno del Congreso, núm. 159, de 15 de marzo de 2006, y Comisión Constitucional, núm. 510, de la misma fecha). 
este Reglamento se establezca sobre quorum y requisitos para la adopción de acuerdos». Lo mismo se desprende implícitamente para el Congreso del establecimiento por el RC de quorum solamente para acuerdos.

Por su parte, la exigencia por el art. 79.1 CE de la asistencia de la mayoría de los miembros de la Cámara ${ }^{15}$ para adoptar acuerdos ha tenido distinto desarrollo en los Reglamentos del Congreso y del Senado.

Conforme al art. $93 \mathrm{RS}$, se presume la presencia del número legal necesario para adoptar acuerdos, que fija en la mitad más uno de los miembros del órgano; no obstante, será necesaria su comprobación cuando antes de iniciarse una votación lo requiera un grupo parlamentario o diez senadores en el Pleno o cinco en la comisión. Cuando se trate de un acto o propuesta que exija mayoría cualificada, el presidente puede disponer que se compruebe la existencia de quorum. Si se comprueba la falta de quorum para adoptar acuerdos, el presidente podrá aplazar la votación hasta el momento que señale. No impone, sin embargo, el RS la repetición de aquellas votaciones (inválidas) respecto de las que se ha comprobado a posteriori que no existía el quorum necesario.

El RC (art. 78.2) se refiere a la verificación del quorum en el momento de la votación — sin indicar a instancia de quién se realiza aquella- o después de celebrada esta, supuesto (por entenderse que la votación no sería válida) que se asimila al primero, posponiéndose en ambos casos la votación ${ }^{16}$ por el plazo máximo de dos horas. Si transcurrido este plazo tampoco pudiera celebrarse válidamente la votación, el asunto será sometido a decisión del órgano correspondiente en la siguiente sesión.

Hoy en día no suelen plantearse problemas de quorum de votación en el Pleno, entre otras cosas por la agrupación de votaciones al final del debate diario. Tampoco en las comisiones, en las que facilita la presencia del número de miembros necesario el sistema de suplencias y sustituciones dentro de cada grupo parlamentario, así como la celebración de las votaciones a hora previamente anunciada (en particular, si coinciden en el tiempo las sesiones de varias comisiones) o al final de la sesión.

Con la regulación del voto telemático, al que nos referiremos más adelante, ambos Reglamentos (arts. 79.3 RC y 93.3 RS por reformas aprobadas el 21 de julio de 2011 y 21 de noviembre de 2013, respectivamente) han

15 Sobre lo que debe entenderse por la mayoría (más de la mitad de los miembros, frente a la mitad más uno de los miembros exigida por nuestras Constituciones históricas, salvo la de 1931 y el art. 93 RS), nos remitimos al concepto de mayoría simple analizado en el epígrafe 4.2.

${ }_{16}$ Respecto de la ya celebrada, no válida, se trataría de una repetición. 
incorporado la regla de computar como presentes en la votación a efectos del quorum para acuerdos — como también lo serán para el cómputo de mayorías - a los miembros de la Cámara que, pese a estar ausentes, hayan sido expresamente autorizados por la Mesa para participar en la misma.

La determinación del quorum para acuerdos ha planteado dudas en aquellos órganos que adoptan estos mediante voto ponderado (las comisiones cuya composición no refleja la del Pleno, las ponencias y subcomisiones o la Junta de Portavoces). Tres son las interpretaciones posibles, sin que ninguna se haya impuesto de forma clara $^{17}$ : computar la mayoría por referencia al número de miembros del Pleno, sobre el número de grupos parlamentarios existentes o sobre el número de miembros del órgano en cuestión.

\section{Mayorías necesarias para la adopción de acuerdos}

\subsection{Clases de mayorías}

La votación es el mecanismo mediante el cual se articula la voluntad de los órganos colegiados. Salvo en aquellos supuestos en que se exige unanimidad, en las votaciones se pone de manifiesto una opinión mayoritaria que se atribuye al órgano, lo que permite la adopción de acuerdos. La regla de mayoría es consustancial a la democracia y se manifiesta singularmente en las Cámaras parlamentarias. Como ha señalado el Tribunal Constitucional [STC 5/1981, FJ 21.a)], «nuestra Constitución ha instaurado una democracia basada en el juego de las mayorías, previendo tan solo para supuestos tasados y excepcionales una democracia de acuerdo basada en mayorías reforzadas» ${ }^{18}$, aunque no es menos cierto que «esas mayorías cualificadas o reforzadas son reconocidas como necesarias cuando la naturaleza o carácter de las decisiones o acuerdos que han de ser tomados lo justifican» (STC 238/2012, FJ 4..$^{\circ}$.

17 Vid. M. Araujo Díaz de Terán, «Quorum», en E. Arnaldo Alcubilla (coord.), Enciclopedia Jurídica, Madrid, La Ley, 2008-2009, p. 10448.

${ }^{18}$ Las minorías deben ser oídas, de acuerdo con el principio clásico «the minority should have its say, the majority should have its way». Así lo recuerda el TC en la Sentencia 139/2017, FJ 5..$^{\circ}$ : «Si bien es cierto que la decisión final del procedimiento corresponde en nuestro ordenamiento por regla general, como es propio del principio democrático, a la mayoría, al ser excepcional la regla de la mayoría cualificada, no es menos cierto, sin embargo, que aquella decisión, por exigirlo así la naturaleza democrática del procedimiento legislativo, no puede adoptarse sin la participación y sin haber oído antes a la minoría». 
Antes de exponer las mayorías requeridas por la Constitución para la adopción de acuerdos en el Congreso y en el Senado distinguiremos las distintas clases de mayoría:

a) Mayoría simple. Se obtiene cuando los votos afirmativos superan a los negativos, sin que se requiera que aquellos alcancen un número determinado, siempre que se respete el número de presentes establecido. La Constitución no utiliza el calificativo «simple», que sí emplean los Reglamentos (arts. 79.1 RC y $93 \mathrm{RS}$ ). La referencia a la mayoría de miembros presentes en el art. 79.2 CE creó algunas dudas teóricas en un primer momento sobre el cómputo de las abstenciones, o, dicho de otro modo, si el número de votos favorables debía superar al de negativos más las abstenciones y los votos en blanco o nulos ${ }^{19}$. Esta duda ha sido solventada por la práctica de modo que solo se exige que los votos a favor superen a los votos en contra, cualquiera que sea el número de unos u otros, o de las abstenciones ${ }^{20}$.

$\mathrm{El}$ art. 79.2 CE contrapone a la mayoría (simple) las especiales —entendiéndose por tales aquellas en que se exige un número de votos favorables que alcance una fracción de los miembros de la Cámara, normalmente superior a la mitad-, que a su vez pueden clasificarse en mayoría absoluta y mayorías cualificadas o reforzadas ${ }^{21}$. La exigencia de mayorías especiales o reforzadas responde al deseo de contar con un cierto consenso a la hora de adoptar determinadas decisiones o de aprobar textos de relevancia, y, en definitiva, de proteger (en alguna medida, en función de la mayoría requerida) a las minorías de la acción de la mayoría, como recuerda el Tribunal Constitucional en la Sentencia 44/1995, en relación con la exigencia de mayoría absoluta para la aprobación del Reglamento parlamentario ${ }^{22}$.

b) Mayoría absoluta. Aunque suele entenderse como aquella en que vota a favor la mitad más uno de los miembros de la Cámara (así aparece, aunque no para la mayoría, sino para el quorum de presencia, en el

19 Vid. E. ReCODER DE CASSO, «Artículo 79», op. cit., pp. 1323 y ss. El ejemplo italiano mostraba soluciones dispares en los Reglamentos de las dos Cámaras.

${ }^{20}$ En el mismo sentido, M. Araujo Díaz de Terán, «Mayoría», en E. Arnaldo AlcubiLLA (coord.), Enciclopedia Jurídica, Madrid, La Ley, 2008-2009, p. 7855.

${ }^{21}$ Calificativos que podrían ser sinónimos de especiales, pero que vamos a reservar para las mayorías que exigen un número de votos favorables superior a la mayoría absoluta.

${ }_{22}$ Y reitera en otras sentencias: «Tal y como se deduce de lo dispuesto en el art. $79 \mathrm{CE}$ y de la interpretación realizada por el Tribunal Constitucional del juego de las mayorías descrito por la norma fundamental [...], la norma generalmente seguida en los procedimientos parlamentarios es el recurso a la mayoría simple, siendo la excepción la previsión de mayorías cualificadas en aras de obtener un mayor consenso "para proteger más eficazmente los derechos e intereses de las minorías, o con otro objeto razonable" (STC 179/1989 de 2 de noviembre, FJ 7. $\left.{ }^{\circ}\right) \gg\left(\right.$ STC 238/2012, FJ 4. ${ }^{\circ}$ ). 
art. 93 RS), la definición correcta ${ }^{23}$ es la que la considera formada por más de la mitad de los miembros de la Cámara, lo que determina una diferencia en el caso de número impar de miembros: la mayoría absoluta de 350 es 176 diputados, de 349 es 175, aunque la mitad más uno sería 176 $(174,5+1=175,5)$. Más de la mitad es la forma de cómputo en las Cámaras.

Dado que el cómputo de la mayoría absoluta, como de las restantes especiales, se realiza sobre el número de miembros de la Cámara, se plantea cuál es el que ha de tomarse a estos efectos, si el de miembros de derecho (350 en el Congreso) o el de los que en ese momento componen la Cámara, en función de que hayan perfeccionado su condición. Este último era el criterio de la Constitución de 1869 y el que se aplica en nuestras Cámaras, al menos desde la III y IV Legislaturas, cuando los parlamentarios electos de Herri Batasuna no accedieron a la plena condición de tales y, en consecuencia, se entendía menor el número de miembros a efectos de cómputo de la mayoría ${ }^{24}$. En la actualidad, se aplica con normalidad en Pleno y comisión cuando un parlamentario renuncia al acta y el que ha de sustituirle, en el momento de celebrarse la sesión, no ha adquirido todavía la plena condición de parlamentario mediante la presentación de su credencial y la prestación de juramento.

c) Mayorías cualificadas o reforzadas. Son aquellas en que, para adoptar determinados acuerdos, se requiere un número de votos favorables superior a la mayoría absoluta (tres quintos, dos tercios). Como veremos a continuación, se exigen en la Constitución para la elección de personas y la aprobación de la reforma constitucional. El número de miembros que se toma como referencia es el mismo que para la mayoría absoluta, los que en ese momento componen la Cámara.

\subsection{Regla general: mayoría simple. Formas de votación}

Conforme dispone el art. 79.2 CE, la regla general de mayoría para la adopción de acuerdos por las Cámaras es la mayoría simple, esto es, en los términos del precepto constitucional, «mayoría de los miembros presentes», a la que los Reglamentos han añadido el calificativo de «simple»

${ }_{23}$ Que confirma el Diccionario de la Real Academia Española: mayoría que consta de más de la mitad de los votos.

${ }^{24}$ En contra de esta interpretación vid. E. Vírgala ForuRIA, «Sobre el concepto de mayoría en el ordenamiento parlamentario español», Revista de las Cortes Generales, núm. 37 (1996), pp. 56 y ss. 
(arts. 79.1 RC y $93 \mathrm{RS})^{25}$. Su carácter de regla general ha sido confirmado por el Tribunal Constitucional en las diversas sentencias citadas desde la Sentencia 5/1981.

La regla de la mayoría, propia de los órganos colegiados y, por otra parte, consustancial a la democracia, se obtiene mediante la votación, cuyo ejercicio constituye un derecho de los parlamentarios reconocido en los Reglamentos (arts. 6.1 RC y 20.1 RS), relacionado con el deber de asistencia (cuyo incumplimiento puede ser sancionado, arts. 15 y 99.1 RC, y 20.1 y 63 RS). El derecho al voto forma parte del ius in officium del parlamentario, integrado en el núcleo de la función representativa. Como declara la STC 361/2006, FJ 3. ${ }^{\circ}$, no parece que puedan plantearse dudas sobre ello: «No ha habido, hasta ahora, un pronunciamiento claro al respecto, pero dicha pertenencia se deriva de la naturaleza misma de las cosas. Uno de los principales derechos/deberes de aquellos es la participación en las tareas de las Cámaras, y la forma más habitual de concretar la misma es el ejercicio de su derecho al voto; ejercicio con el que manifiestan su postura en los acuerdos de las Asambleas».

La forma de las votaciones ha sufrido una evolución en la práctica desde la aprobación de la Constitución y de los propios Reglamentos (arts. 78 a 89 RC y 92 a 100 RS). Las votaciones en Pleno se celebran usualmente por procedimiento electrónico. Aunque los Reglamentos prevén también como forma ordinaria de votación el levantarse sucesivamente aquellos que aprueban, desaprueban o se abstienen, el procedimiento electrónico, también previsto como ordinario en los Reglamentos (arta. 84 RC y $95.1 \mathrm{RS})$, se ha impuesto absolutamente ${ }^{26}$.

${ }_{25}$ Este último precepto concatena adecuadamente las reglas de quorum y mayoría establecidas en los apartados 1 y 2 del art. 79 CE: «Los acuerdos se adoptarán por mayoría simple de senadores presentes, siempre que lo esté la mitad más uno de sus miembros». Establece, no obstante, una interpretación de la mayoría simple para el quorum de presencia que, como hemos señalado, no es la única posible, ni desde luego la seguida en ambas Cámaras para la adopción de acuerdos: la mayoría de sus miembros a que alude el art. 79.1 CE no tiene por qué ser la mitad más uno, bastando más de la mitad, lo que conlleva una diferencia en los casos en que la Cámara se compone de un número impar de miembros.

26 Durante las votaciones, las puertas del salón de sesiones se cierran y no se permite la entrada de parlamentarios. Ello es consecuencia de lo dispuesto en los arts. 50 RC y 95.2 RS; según el primero, «las votaciones no podrán interrumpirse por causa alguna. Durante el desarrollo de la votación la presidencia no concederá el uso de la palabra y ningún diputado podrá entrar en el salón ni abandonarlo». Este precepto estaba previsto para las votaciones ordinarias sin procedimiento electrónico, en desuso en el Pleno, que consumen un cierto periodo de tiempo cada una de ellas, al componerse cada decisión de varias votaciones sucesivas (los que aprueban, desaprueban y se abstienen, en su caso, por filas). Para paliar este efecto, con mayor o menor flexibilidad según las legislaturas, se abrirán las puertas entre 
Se aprueban por asentimiento las decisiones que cuentan con unanimidad, incluyendo a veces asuntos no internos o de procedimiento (como son las modificaciones del orden del día o la avocación de proyectos y proposiciones en el Congreso), sino sustantivos (aprobación de dictámenes sobre convenios internacionales). El Reglamento del Congreso prescribe la votación nominal pública ${ }^{27}$ por llamamiento para las decisiones relacionadas con el otorgamiento de la confianza de la Cámara (investidura, moción de censura y cuestión de confianza, art. 85.2 RC), así como la fijación anticipada del momento de celebración (también para la votación final de conjunto de los proyectos y proposiciones de ley orgánica) y la votación por papeletas para la elección de personas (asimismo, cuando lo decida la Presidencia o se especifique en la solicitud de voto secreto). El Reglamento del Senado impone la votación nominal por papeletas para la designación de cargos y por bolas blancas y negras en los casos de calificación de actos o conductas personales (incompatibilidades y suplicatorios) ${ }^{28}$.

Puede realizarse votación secreta (nominal o electrónica), además de cuando lo exige el Reglamento, a petición de dos grupos parlamentarios o una quinta parte de los diputados (art. 85.1 RC) o de cincuenta senadores (art. 97.1 RS). El art. 85.1 RC prohíbe la votación secreta en los procedimientos legislativos o en aquellos casos en los que los acuerdos hayan de adoptarse en función de criterios de voto ponderado, supuesto este último no aplicable a las sesiones plenarias ${ }^{29}$.

Los empates se solventan repitiendo la votación hasta dos veces (espaciadas tras una suspensión en el Congreso) y, si el empate persiste, se entiende desechado el texto objeto de la votación (arts. 88.1 RC y 100.1 RS). En el Senado, el empate en papeletas obliga a la repetición de votaciones hasta que aquel se resuelva (art. 100.2 RS, igual para designaciones

dos votaciones, de vez en cuando o cuando se conozca que algún parlamentario desea incorporarse al Pleno.

27 Pueden solicitarla, asimismo, dos grupos parlamentarios o una quinta parte de los diputados (art. 85.1 RC) o cincuenta senadores (art. 96.1 RS).

${ }^{28}$ La Norma supletoria de 9 de octubre de 2007 admite, no obstante, la votación de los dictámenes de la comisión de suplicatorios por el Pleno por procedimiento electrónico, decidiendo el presidente de acuerdo con la Mesa si ha de aplicarse aquel o la votación por papeletas.

29 Esta prohibición de votación secreta, al igual que el carácter ordinario de la votación pública (por otra parte, consustancial a la publicidad de las actuaciones parlamentarias), refuerza la disciplina del grupo parlamentario, que aplica sanciones pecuniarias a la no asistencia y a la votación, deliberada o por error, en contra de sus indicaciones, lo que incide claramente en la libertad de voto. Recordemos que el art. 67.2 RC declara que los miembros de las Cortes Generales no están ligados por mandato imperativo. 
en arts. 37.3 y 204.6 RC) y el empate a bolas blancas y negras equivale a la mayoría de bolas blancas (aprobación de la conducta calificada, arts. 100.3 y 97.2 RS), es decir, que el resultado es pro senador.

$\mathrm{Ni}$ el Reglamento del Senado ni el del Congreso prevén la anulación y repetición de aquellas votaciones en las que el resultado no responde a la voluntad de la Cámara, por error o deficiente funcionamiento del sistema (electrónico). Esto último, a veces, no es imputable al mismo, sino a la comprensible inexperiencia en su funcionamiento por sus usuarios al comienzo de la legislatura o en otras situaciones.

No obstante, en el Congreso existen escasos precedentes de que se haya repetido una votación en el Pleno, aunque se conozca con toda certeza que un grupo ha expresado erróneamente su voluntad, lo que ha influido en el resultado ${ }^{30}$. Sí puede ocurrir que, en el curso de una votación que el presidente declara iniciada, la anule antes de finalizar el tiempo para que los diputados pulsen su botón de voto porque aprecie que ha enunciado incorrectamente el objeto de la votación (números de enmiendas o identificación de la parte del dictamen, por ejemplo). Pero más allá de esta rectificación sobre la marcha, el resultado erróneo será proclamado como tal ${ }^{31}$. Un ejemplo claro a este respecto constituye la aprobación de una enmienda a la totalidad por error en la votación por parte del Grupo Popular en la VII Legislatura ${ }^{32}$.

En el Senado consta algún precedente de repetición de votación, bien por acuerdo de la Mesa, bien por decisión del presidente en el curso del debate. A diferencia de la rigidez con que se aplica en el Congreso la imposibilidad de anulación de una votación ${ }^{33}$ (salvo cuando no ha funcionado el sistema y se anula antes de que tenga lugar), en el Senado se han

30 Sobre esta cuestión vid. P. GARCía-Escudero MárQuez, El procedimiento legislativo ordinario en las Cortes Generales, Madrid, Centro de Estudios Políticos y Constitucionales, 2006, pp. 468 y ss. y 611 y ss., con ejemplos de repetición o anulación de votaciones en ambas Cámaras.

31 En su caso, el diputado o grupo que se ha equivocado hará constar, a efectos del Diario de Sesiones, el verdadero sentido de su voto. Vid., por ejemplo, Diario de Sesiones del Pleno del Congreso, núm. 25, 21 de julio de 2004, p. 1123. Puede verse un supuesto diferente, de protesta porque el resultado no se ajustaba al número real de diputados presentes en la Cámara, en el Diario de Sesiones, núm. 155, 18 de abril de 2002.

32 Como figura en el Diario de Sesiones del Pleno del Congreso, núm. 66, 8 de marzo de 2001, presentada al proyecto de ley de reforma del texto articulado de la Ley sobre tráfico, circulación de vehículos a motor y seguridad vial. No se repitió la votación y la devolución del proyecto tuvo que ser corregida mediante el envío de un nuevo proyecto de ley por el Gobierno, cuyo acuerdo de solicitud de tramitación por el procedimiento de urgencia se fundamentaba en el error padecido en la Cámara.

33 Vid. por ejemplo, Diario de Sesiones del Congreso, núm. 56, 10 de marzo de 1994, pp. 2763 y ss., y núm. 193, 12 de noviembre de 1998, pp. 10289 y ss. 
dado algunos supuestos de anulación de una votación válidamente celebrada en Pleno ${ }^{34}$.

Obviamente, se entiende siempre que solo cabe repetir una votación si nadie se opone a ello ${ }^{35}$. Esto se quebró también al inicio de la VIII Legislatura ${ }^{36}$.

En todo caso, creemos que sería bueno introducir en los Reglamentos la posibilidad de repetición de una votación manifiestamente errónea o deficiente (ya prevista en algún Reglamento autonómico, como, por ejemplo, en el art. 127.2 del Reglamento de la Asamblea de Madrid) si ningún miembro de la Cámara se opone; cautela que protegería a las minorías de cualquier intento de maniobra, pero que permitiría enderezar determinados resultados que claramente no se corresponden con la voluntad de la Cámara.

Son aplicables (así lo dispone expresamente el art. $64 \mathrm{RS}$ ) a las votaciones en comisión las reglas generales sobre las votaciones. La forma ordinaria de votación en comisión es a mano alzada (aunque esta no figura en los Reglamentos, sino la votación levantándose y sentándose, otrora usual en los Plenos cuando no existía el procedimiento electrónico), aplicándose también la aprobación por asentimiento (arts. 83 RC y 94 RS) y la votación por papeletas cuando tenga carácter secreto y para la elección de car-

34 Como la anulación posterior por la Mesa (acuerdo de 13 de mayo de 1991) de las votaciones realizadas sobre el Proyecto de Ley del Impuesto sobre la Renta de las Personas Físicas (vid. Diario de Sesiones del Senado, núm. 69, 16 mayo de 1991, p. 3801), respecto de las cuales la prensa había publicado fotos que probaban el voto de unos senadores por otros, incluso con el pie, y que dio lugar a la repetición de las votaciones en otra sesión plenaria. R. M. Fernández Riveira, El voto parlamentario, Madrid, Centro de Estudios Políticos y Constitucionales, 2003, pp. 314 y ss., recoge este precedente, así como algún otro de anulación por problemas técnicos en el reloj que marcaba el tiempo de votación (Diario de Sesiones del Senado, núm. 25, 17 de diciembre de 1996, p. 972) o por error (Diario de Sesiones del Senado, núm. 113, 15 de diciembre de 1998, p. 5427). Los más antiguos del lugar recordamos también la anulación de la elección de don Carlos Ollero Gómez como consejero del Tribunal de Cuentas por la confusión producida en sus apellidos, el 28 de junio de 1982, repitiéndose la elección al día siguiente (Diario de Sesiones del Senado, núm. 167, 29 de junio 1982, pp. 8242-8243). Vid. también un supuesto más reciente de anulación de un voto efectuado por un asistente, infra epígrafe 5.5.

35 Así, en el Diario de Sesiones del Senado, núm. 146, 17 de diciembre de 1992, pp. 81968198. La oposición de un senador de Izquierda Unida (aunque el portavoz del Grupo Mixto había admitido la repetición) motivó que esta no se produjera. Aunque el senador citado declaró finalmente su disposición a ausentarse del Pleno para que «se pongan de acuerdo los grupos mayoritarios», el portavoz del Grupo Popular manifestó que sería suficiente con que el debate constara en el Diario de Sesiones.

36 Vid. Diario de Sesiones del Senado, núm. 3, 12 de mayo de 2004, p. 5961, en el que el presidente repite la votación de una moción a solicitud de los representantes de varios grupos parlamentarios que alegaron no haber oído la expresión «comienza la votación», y a pesar de la protesta del representante del grupo mayoritario. 
gos (arts. 87.1.2. ${ }^{\circ} \mathrm{RC}$ y $\left.97.2 \mathrm{RS}\right)^{37}$, pero no la votación por bolas blancas y negras prevista en el Senado para el Pleno.

Cabe solicitud de votación pública por llamamiento por dos grupos parlamentarios o una quinta parte de los miembros de la comisión (art. 85.1 RC; cinco miembros en el Senado, art. 96.1 RS). Asimismo, pueden solicitar votación secreta dos grupos o un quinto de los miembros de la comisión en el Congreso (art. 85.1 RC, o un tercio de los miembros en el Senado, art. 97.1 RS), pero esta votación está excluida en el Congreso para los procedimientos legislativos ${ }^{38}$. No suelen darse estas formas de votación en comisión, como tampoco se aplica el procedimiento electrónico, estando instalado el sistema solo en los salones de Plenos, aunque comienzan a adecuarse técnicamente algunas salas de comisiones.

Los empates en las votaciones de comisión, a partir de sendas reformas de los Reglamentos de 23 de septiembre de 1993 (Congreso) y 24 de octubre de 1995 (Senado), pueden dirimirse («se entenderá que no existe empate») ponderando el número de votos con que cada grupo cuente en el Pleno, cuando sea idéntico el sentido del voto de todos los miembros de la comisión pertenecientes a un mismo grupo parlamentario (arts. 88.2 RC y 100.4 RS ${ }^{39}$. Este precepto, cuyo precedente se sitúa en una Resolución de la Presidencia del Congreso de los Diputados de 27 de abril de $1979^{40}$, se aplica con mayor frecuencia en aquellos momentos en que las comisiones están integradas por un número par de miembros, que propicia los empates ${ }^{41}$.

${ }^{37}$ Los diputados no pueden tomar parte en las votaciones sobre resoluciones que afecten a su estatuto de diputado (art. 79.2 RC).

${ }^{38}$ En caso de solicitudes concurrentes (pública por llamamiento o secreta), prevalece la votación secreta en el Congreso (art. 85.1 RC) y en el Senado se somete previamente a votación como cuestión incidental el procedimiento que debe aplicarse.

39 En ambos reglamentos destaca la complejidad de la fórmula utilizada, que admite varias interpretaciones posibles: estando presentes todos los miembros de la comisión, o todos los miembros de los grupos presentes cuyo número se pondera, o una tercera interpretación, que es la que aplica la Dirección de Comisiones de la Secretaría General del Congreso (y, por tanto, los letrados adscritos a la misma), según la cual, si el sentido del voto es idéntico, es indiferente cuántos miembros de cada grupo estén presentes, bastando con la presencia de un solo miembro del grupo parlamentario para que este sea tenido en cuenta en la ponderación; criterio aplicado también en las ponencias.

40 Según la cual: «Se entenderá que existe acuerdo sobre una cuestión cuando, no obstante producirse igual número de votos a favor y en contra de la propuesta debatida en la comisión, todos los vocales de cada uno de los grupos parlamentarios presentes en aquella hayan votado en sentido idéntico y el número de escaños que corresponden en el Pleno a todas las formaciones políticas que han votado en un sentido superen al de aquellas otras cuyos miembros hayan votado en sentido adverso» (BOCG Congreso, Serie H, núm. 4, 2 de mayo de 1979).

${ }^{41}$ Sobre los problemas que plantea la ponderación de voto cuando el Grupo Mixto cuenta con dos miembros en las ponencias y comisiones, vid. P. GARCía-EsCudERo MÁrQuez, 
En caso de que no pueda dirimirse así el empate, es de aplicación la regla general para la resolución de empates en las votaciones: repetición de la votación por dos veces (la segunda - tercera votación-, en el Congreso, tras una suspensión por el plazo que estime razonable la presidencia); caso de producirse nuevo empate, se entenderá desechado el dictamen, artículo, proposición, enmienda, voto particular o cuestión de que se trate (arts. 88.1 RC y 100.1 y 2 RS).

\subsection{Mayorías especiales}

El art. 79.2 CE excepciona de la regla de la mayoría simple para la obtención de acuerdos por las Cámaras las mayorías especiales que establezcan la Constitución o las leyes orgánicas y las que para elección de personas establezcan los Reglamentos de las Cámaras. El fundamento de la exigencia de estas mayorías especiales, como ha destacado el Tribunal Constitucional, se encuentra en el deseo de obtener un mayor consenso cuando la naturaleza o carácter de las decisiones lo justifican (STC 238/2012, FJ 7. ${ }^{\circ}$ ), en particular para proteger más eficazmente los derechos de las minorías (SSTC 179/1989, FJ 7.'; 44/1995, FJ 3. ${ }^{\circ}$, y 239/2012, FJ 4. ${ }^{\circ}$ ).

a) Los supuestos para los que la Constitución exige mayoría absoluta (voto a favor de más de la mitad de los miembros que en ese momento componen la Cámara) son los siguientes:

- aprobación y reforma de los Reglamentos de las Cámaras y del Reglamento de las Cortes Generales (art. 72.1 y 2 CE),

— petición de sesión extraordinaria (art. 73.2 CE),

- decisión final del Congreso en las discrepancias entre las Cámaras sobre los supuestos establecidos en el art. 74.2 CE [arts. 94.1 (autorización de tratados internacionales), 145.2 (autorización de acuerdos de cooperación entre Comunidades Autónomas) y 158.2 (distribución del Fondo de Compensación Interterritorial)],

- declaración de una sesión plenaria como secreta, si el Reglamento no exige otra cosa (art. $80 \mathrm{CE}$ ),

- del Congreso, para la aprobación, modificación y derogación de leyes orgánicas, en votación final sobre el conjunto (art. $81 \mathrm{CE}$ ),

«Un nuevo Parlamento fragmentado para los cuarenta años de la Constitución», Revista de Derecho Político, núm. 101 (2018), pp. 79 y ss. 
- del Senado, para la aprobación de un veto a proyectos (y proposiciones) de ley; del Congreso, para levantamiento inmediato del veto del Senado mediante ratificación del texto inicial (art. 90.2 CE),

- del Congreso, otorgamiento de la confianza en primera vuelta al candidato a presidente del Gobierno propuesto por el rey (art. 99.3 CE),

- del Congreso, para la adopción de una moción de censura (art. 113.1 CE),

- del Congreso, para la autorización del estado de sitio (art. 116.4 CE),

- apreciación de la necesidad para dictar leyes de armonización (art. 150.3 CE),

- del Senado, aprobación de medidas excepcionales hacia una Comunidad Autónoma (art. 155.1 CE),

- del Senado, sobre el texto de la comisión mixta para que el Congreso pueda solventar finalmente las discrepancias en la reforma constitucional ordinaria (art. 167.2 CE).

La Constitución exige mayoría reforzada o cualificada de tres quintos (se interpreta, como todas las mayorías especiales, de los miembros que en ese momento componen la Cámara) para la elección de miembros del Consejo General del Poder Judicial (art. 122.3 CE) y del Tribunal Constitucional (art. 159.1 CE), así como para la aprobación de la reforma constitucional ordinaria (art. 167.1 CE).

También en la reforma constitucional ordinaria se exige mayoría de dos tercios del Congreso para la aprobación del texto de la comisión mixta que hubiera obtenido al menos la mayoría absoluta del Senado (art. 167.2 CE). Para la aprobación de una reforma constitucional agravada se requieren dos tercios en cada una de las Cámaras en dos legislaturas sucesivas (aprobación del principio de reforma en la primera y del nuevo texto constitucional en la segunda).

Distintas leyes orgánicas establecen mayorías especiales de las Cámaras para la elección de cargos $^{42}$ : así, tres quintos para la elección del Defensor

42 Por Resolución de la Presidencia del Congreso de 25 de mayo de 2000, relativa a la intervención de la Cámara en el nombramiento de las autoridades del Estado, se regula el procedimiento para los supuestos en que el Congreso haya de efectuar una propuesta para la designación de personas o proceder al nombramiento directo de estas, que incluye la posibilidad de comparecencia previa ante la comisión consultiva de nombramientos, integrada por el presidente del Congreso y los portavoces de los grupos parlamentarios. La comisión trasladará al Pleno su criterio sobre la idoneidad de los candidatos. En el Senado, la reforma del Reglamento de 14 de junio de 2000 incorpora esta comisión entre las no legislativas y regula su actuación (estableciendo el voto ponderado para la adopción de los acuerdos) 
del Pueblo (LO 3/1981, para sucesivas propuestas mayoría de tres quintos en el Congreso y absoluta en el Senado) y de los miembros del Tribunal de Cuentas (LO 2/1982). La elección de los miembros del Observatorio de la Vida Militar se hace por el Congreso y por el Senado por mayoría absoluta con el apoyo de, al menos, tres grupos parlamentarios en cada Cámara (LO 9/2011, de 27 de julio, de derechos y deberes de los miembros de las Fuerzas Armadas). La LO 3/2013 prevé la posibilidad de veto, por mayoría absoluta de la comisión competente del Congreso, al nombramiento del candidato propuesto por el Gobierno para miembro, presidente o vicepresidente de la Comisión Nacional de los Mercados y de la Competencia.

Aunque el art. 79.2 CE habilita solo a las leyes orgánicas para requerir mayorías parlamentarias especiales, algunas leyes ordinarias también establecen estas mayorías para determinados nombramientos, lo que podría suponer la vulneración de la reserva constitucional a favor de los Reglamentos de las Cámaras. Así, dos tercios para los miembros del Consejo de Administración y del presidente de la Corporación RTVE (Ley 17/2006, modificada por Ley 5/2017). La Ley 5/1980, de 22 de abril (art. 5), de Creación del Consejo de Seguridad Nuclear, requiere para el nombramiento del presidente y los consejeros por el Gobierno la previa aprobación o el veto razonado por el Congreso a través de la comisión competente, que decide por mayoría de tres quintos.

b) $\mathrm{El}$ art. 79.2 CE permite a los Reglamentos de las Cámaras establecer mayorías especiales para la elección de personas. Al amparo de este artículo, los Reglamentos requieren mayoría absoluta para elegir en primera votación al presidente de la Cámara (arts. 37.1 RC y 7.1 RS), celebrándose en su defecto nueva votación entre los dos que hubieran obtenido mayor número de votos, de la que resultará elegido el que obtenga más votos.

A las reglas de elección de la Mesa de la Cámara se remite la elección de las Mesas de las comisiones (arts. $41 \mathrm{RC}$ y $53.3 \mathrm{RS}$ ), por lo que los presidentes de comisión han de elegirse, asimismo, por mayoría absoluta en primera vuelta.

Los Reglamentos reproducen las exigencias constitucionales de mayoría absoluta o reforzada. Además, el Reglamento del Senado requiere mayoría absoluta para acordar la suspensión en la condición de senador tras la concesión de suplicatorio (art. 22.6 RS), supuesto no incluible en el ámbito que el art. 79.2 CE otorga a los Reglamentos para fijar mayorías

en el art. 185. Al igual que en el Congreso, la comisión somete al Pleno un informe sobre la idoneidad de los candidatos. 
especiales. Tampoco cabe entender comprendida en este ámbito la exigencia de mayoría absoluta por el art. 159 RS, en el procedimiento agravado de reforma constitucional, para la ratificación del principio de reforma por la segunda legislatura.

\section{Jurisprudencia constitucional sobre voto electrónico}

Distintos incidentes se han suscitado, en particular en Parlamentos autonómicos, como consecuencia de la introducción del sistema de voto electrónico, que han dado lugar a pronunciamientos del Tribunal Constitucional.

Sobre el voto de un diputado por otro - lo que nos lleva, en definitiva, a la indelegabilidad del voto que analizamos en el apartado siguiente- en el Parlamento Vasco ${ }^{43}$, sea votando efectivamente, sea pulsando el botón de presencia que permite el cómputo de la mayoría, el Tribunal afirma (STC 129/2006, FJ 6. ${ }^{\circ}$ ): «En ningún caso resulta dudoso que en ambas hipótesis el parlamentario, al pulsar el botón que no le corresponde, está suplantando la personalidad de otro parlamentario y con ello infringiendo el deber de respeto de los procesos y mecanismos de votación, que es, en definitiva, el fundamento de la subsunción de la conducta en la norma sancionadora [...] activando el mecanismo de botón de presencia de otro parlamentario, además del suyo propio, el demandante de amparo modificó los términos de la votación en curso, toda vez que la mayoría necesaria para el éxito de la propuesta sometida a votación solo se determina por relación al número de parlamentarios presentes [...] No resulta baladí recordar que tanto el art. 79.3 CE, al que se refiere el acuerdo sancionador, como los usos parlamentarios determinan el carácter personal e indelegable del voto; de manera que, por formar parte del núcleo esencial de las reglas de ordenación de la función parlamentaria, un parlamentario no puede alegar su desconocimiento sin que dicho desconocimiento implique paralelamente la infracción de la lex artis parlamentaria, pues el primero de los deberes que configuran la lex artis en el ejercicio de cualquier profesión o cargo reside en procurarse el conocimiento de las reglas básicas conforme a las cuales ha de ejercerse la profesión o cargo [...] por lo que no puede considerarse imprevisible para un parlamentario que la conducta de pulsar el botón de presencia de otro parlamentario es

${ }^{43}$ Ni el Estatuto de Autonomía ni el Reglamento del Parlamento Vasco recogían la personalidad e indelegabilidad del voto parlamentario. 
una conducta sancionable por infringir los deberes del recto ejercicio del cargo de parlamentario».

La STC 361/2006 resuelve el recurso de amparo de una diputada del Parlamento Vasco que alegó no poder votar, a pesar de que se encontraba en su escaño e intentó accionar el mecanismo electrónico. El presidente se negó a que se repitiera la votación y dio por bueno el resultado. El Tribunal declara que en un caso en que resulta afectado el derecho fundamental de un parlamentario, «recae sobre los órganos de la Cámara, y en especial sobre su presidente, la tarea de demostrar que la diputada tuvo una conducta negligente. Puede presumirse, por el contrario, que, salvo prueba indubitable en contrario, la misma actuó correctamente, entre otras cosas porque ningún interés puede suponérsele en crear una situación en la que ella y su grupo fueron los principales perjudicados. De los datos que constan en el expediente y de las alegaciones hechas por las partes se deduce que no se ha podido probar, de manera irrebatible, que la señora Novales cometiera un error durante el desarrollo de la votación»; de esta forma se invierte la carga de la prueba y se hace recaer la responsabilidad sobre la Presidencia ${ }^{44}$. El Tribunal concluye que la actuación de la presidencia «supuso, pura y simplemente, lesionar el derecho a votar de la parlamentaria. No es lógico entender que, ante un problema técnico, que puede suponer con mayor o menor frecuencia en ese tipo de sistemas electrónicos y sin que por otra parte haya quedado fehacientemente demostrado que se tratara de una negligencia de la diputada, la única reacción presidencial fuera la negativa a la comprobación de la anomalía en ese momento y a la repetición, en su caso, de la votación controverti$\mathrm{da}$, con las graves consecuencias que ello implicaba para el resultado de la misma y para el conocimiento de la auténtica voluntad de la Cámara en tema tan trascedente para la Comunidad Autónoma como era la aprobación de su Ley de presupuestos» $\left(\mathrm{FJ} 3 .^{\circ}\right)$.

${ }^{44}$ Vid. el comentario de esta sentencia en P. GarCía-Escudero MÁrQueZ, «¿Es posible repetir las votaciones parlamentarias? ¿Vota el diputado o el grupo parlamentario? A propósito de la STC 361/2006», Teoría y realidad constitucional, núm. 20 (2007), pp. 611-631, donde se rechaza este criterio, manteniendo — con el voto particular a la sentencia - que el deber genérico que recae sobre los órganos de la Cámara, y en especial sobre el presidente, no es demostrar que un diputado tenga una conducta negligente, sino asegurarse $-\mathrm{O}$ al menos poner los medios para verificar- de que los sistemas de votación funcionan o han funcionado correctamente y tomar las medidas oportunas en caso contrario. Es decir, lo que corresponde a la Presidencia es observar la máxima diligencia, porque lo que está en juego no es solo el derecho al voto de un diputado, sino también que la voluntad de la Cámara sea correctamente expresada y reflejada en el acuerdo adoptado. 


\section{EL VOTO PERSONAL E INDELEGABLE}

\section{Evolución y sistemas en Derecho comparado}

El art. 79.3 CE declara el carácter personal e indelegable del voto de senadores y diputados, en la línea — aun sin proclamación expresade la mayor parte de los Parlamentos, que imponen la presencia de sus miembros para poder votar, con la consiguiente exclusión del voto por delegación. Existen, no obstante, algunas excepciones o matizaciones a esta afirmación.

La excepción más clara la constituye el modelo francés de voto por delegación o procuration (también en Luxemburgo y algunos Parlamentos africanos), así como los supuestos en que se admite el voto a distancia, que mantiene la personalidad e indelegabilidad pero no exige la presencia. Son matizaciones el sistema de pairing — basado en la cortesía parlamentaria, practicado tradicionalmente en el Reino Unido, Irlanda, Estados Unidos y Canadá, y también en otros países como Bélgica-y algunos supuestos de sustitución temporal.

\subsection{Pairing}

Aparte de la indelegabilidad y del voto por delegación, un tercer modelo que afecta a la personalidad del voto es el sistema de pairing, práctica consistente en emparejar a los ausentes de distintas formaciones políticas (es propia, por tanto, de sistemas bipartidistas) para paliar la rigidez del sistema de voto personal: un parlamentario que no estará presente en una votación solicita de uno de opinión contraria que no participe en las votaciones que tengan lugar durante su ausencia para mantener el equilibrio entre mayoría y minoría.

En el Reino Unido, el pairing es una práctica inveterada en ambas Cámaras. Erskine May afirma que no cabe el reconocimiento parlamentario de este uso, aunque nunca ha sido expresamente condenado, rechazándose una moción en este sentido en $1743^{45}$. Se desarrolla de forma particular entre parlamentarios individuales o concertado por los whips de los

${ }^{45}$ E. May, Treatise on the Law, Privileges, Proceedings and Usage of Parliament, 19. ${ }^{a} \mathrm{ed} .$, London, Butterworths, 1976, p. 402. 
partidos ${ }^{46}$. El pairing, no obstante, no resuelve los problemas que plantea la maternidad o las ausencias por enfermedad en el Parlamento británico. Así lo reconoce un informe oficial ${ }^{47}$, que concluye que hasta entonces los tres principales partidos parlamentarios no se habían preocupado seriamente por la paternidad, la maternidad ni el permiso para el cuidado de hijos. La recomendación con respecto al pairing es que debería existir una mayor transparencia en su organización que contribuyera a que las solicitudes de licencia por enfermedad o cuidado de personas dependieran en menor medida del estado de las relaciones entre los partidos y las circunstancias del momento.

El caso de Bélgica presenta interés por cuanto el pairage encuentra reflejo en los textos reglamentarios: el art. 57 del Reglamento de la Cámara de Representantes, bajo la rúbrica «De las explicaciones de voto y los motivos de abstención», establece que antes de proceder a la votación nominativa aislada o agrupada, el presidente solicita que se anuncien los motivos por los cuales un miembro se pone de acuerdo con un miembro ausente para abstenerse en la votación, motivos que no dan lugar a debate.

\subsection{Voto por delegación}

El carácter personal del voto es reconocido en la mayor parte de los reglamentos parlamentarios de los países de nuestro entorno. El Reglamento de la Asamblea de Portugal (art. 93) declara expresamente que no se admite el voto por delegación o por correspondencia ${ }^{48}$. Con la excepción de Francia y Luxemburgo, así como algunos países africanos que

${ }^{46}$ May cita estos arreglos entre las funciones de los whips. Vid. ibid., p. 245.

47 Speakers's Conference on Parliamentary Representation Final Report, publicación ordenada por la Cámara de los Comunes el 6 de enero de 2010. Vid. en especial su apartado 7, titulado «Parliament: changing the culture of an institution», entre cuyos epígrafes se encuentran «Support for families, Maternity leave, Statutory maternity cover and MPs, Childcare, Pairing, Sitting hours, Civil Partnerships...».

${ }^{48} \mathrm{Ni}$ la Constitución italiana ni los Reglamentos de la Cámara de Diputados y el Senado recogen el principio del voto personal; la práctica muestra supuestos de voto ejercido por el grupo parlamentario en nombre de sus miembros ausentes, pero los reglamentos no autorizan la delegación de voto. La Corte Costituzionale, en la Sentencia 379/1996, se refiere a un supuesto en que en una sesión varios diputados votaron dos veces ocupando la identidad de diputados ausentes. La Corte proclamó el principio de autonomía parlamentaria, que sustrae al Derecho común lo relativo a los comportamientos de los miembros de la Cámara, de forma que la garantía de que el voto sea ejercitado personalmente debe ser prestada por los Reglamentos parlamentarios. 
siguen el modelo francés, no suele admitirse el voto por delegación ${ }^{49}$, que a veces es expresamente excluido por los reglamentos, como en Suiza. Se suele criticar el voto por delegación por el absentismo que puede provocar, argumentándose como ventaja que permite evitar los efectos de las votaciones por sorpresa, especialmente cuando la mayoría es ajustada.

Debe destacarse en primer lugar que, en los dos países europeos en que existe el voto por delegación, este se encuentra reconocido en el propio texto constitucional. En la Constitución de Luxemburgo (art. 65), con carácter general: «Se admite el voto por delegación. No obstante, nadie puede recibir más de una delegación» ${ }^{50}$. El art. 114 excluye el voto por delegación para los procedimientos de reforma constitucional y para las leyes de aprobación de tratados que transfieran el ejercicio de atribuciones soberanas a instituciones internacionales, a los que el Reglamento añade algún supuesto de votación secreta.

En Francia suele relacionarse en la doctrina la admisión de la delegación de voto en el Parlamento con el constante absentismo, un mal del que ya se halla rastro en dos Decretos de 1790 en los que se establece la exigencia de elaborar una lista de ausencias y la consiguiente privación de la indemnización durante la ausencia del parlamentario ${ }^{51}$.

Incorporado el voto por delegación a la Constitución de 1958 (como excepción para poder afirmar la regla de no delegación) con el límite de una recepción de voto por parlamentario, la Ordonnance 58-1066, de 7 de noviembre de 1958, sobre ley orgánica de autorización excepcional a los parlamentarios a delegar su derecho de voto, regula los amplios supuestos en que ello es posible y sus requisitos ${ }^{52}$. El Reglamento de la Asamblea

49 Constituye, asimismo, una excepción el Bundesrat alemán, por cuanto no se trata de una Cámara propiamente parlamentaria. Como es sabido, está integrada por representantes de los gobiernos de los Länder en función de su población, en número de 3 a 6 . Los votos de cada Land se formulan en bloque, bastando con que uno de sus representantes esté presente, pues el presidente acepta el voto de un miembro individual como voto de todo el Land, siempre que otro miembro del mismo no vote en sentido distinto: si el voto no es unánime en el seno de cada Land, no es válido.

50 De conformidad con el art. 44 del Reglamento, cada diputado tiene derecho a otorgar a uno o a varios de sus colegas delegación de voto en su nombre en caso de ausencia.

${ }^{51}$ Para la evolución del voto por delegación en la historia constitucional francesa vid. P. GARCíA-Escudero Márquez, «Voto parlamentario no presencial y sustitución temporal de los parlamentarios», Corts, núm. 24 (2010), pp. 87 y ss.

52 El Consejo Constitucional, en Decisión núm. 61-16, de 22 de diciembre de 1961, declaró no conforme a la Constitución un supuesto más de delegación añadido por Ley Orgánica de 3 de enero de 1962: ausencias por motivo de las obligaciones derivadas del ejercicio del mandato parlamentario o de un mandato en los consejos electos de las colectividades territoriales de la República, esto es, derivadas de la compatibilidad de mandatos. 
Nacional admite la transferencia de la delegación a otro diputado. Una Instrucción General de la Mesa de la Asamblea Nacional ha hecho posible la compatibilidad de la notificación de la delegación con el sistema de voto electrónico y excluye la delegación para las votaciones secretas. Esta prohibición, al introducirse en la instrucción, eludió el control previo de constitucionalidad, pero el Consejo Constitucional, ejercitando de oficio este control, declaró en la Decisión 73-49, de 17 de mayo de 1973, la no conformidad con el art. 27 de la Constitución de similar prohibición contenida en el art. 64.1 RS, entendiendo que no cabía limitar o restringir la delegación de voto a las votaciones públicas, puesto que la declaración constitucional se refiere a la delegación en general sin límite alguno, y que la prohibición era contraria al espíritu de la Ordenanza de 1958 y su modificación de 1962 que establece los supuestos de posibilidad de delegación ${ }^{53}$.

\subsection{Sustitución temporal de parlamentarios}

La sustitución temporal de parlamentarios, como medio para solucionar los problemas planteados por determinados supuestos en la prestación de voto o en el ejercicio de las funciones parlamentarias, comienza a abrirse paso en algunos países. En estos casos, la normativa reglamentaria ha de concordarse con la legislación electoral en cuanto a la previsión del acceso de un suplente a la condición de parlamentario y la pérdida posterior de esta condición.

Así, el Reglamento del Parlamento de Finlandia establece la suspensión en el mandato de un representante durante su mandato como miembro del Parlamento Europeo. Durante este tiempo sustituye al representante un suplente, que será el primer candidato no electo de la lista del partido o coalición a la que representa el parlamentario (art. 92 de la Ley Electoral). Asimismo, contemplan supuestos de licencia temporal, con la consiguiente sustitución, los Reglamentos de las Cámaras de Dinamarca, Suecia, Noruega y Holanda (Cámara Baja). En Portugal, la propia Constitución (art. 153) remite a la ley electoral la regulación de la sustitución

Las razones para su inconstitucionalidad fueron la excesiva generalidad de la disposición, la falta de control por parte de los órganos parlamentarios y el no cumplimiento del carácter excepcional que la Constitución francesa exige para la autorización del voto no personal.

53 Numerosas incidencias se han planteado en la aplicación de los preceptos mencionados. Vid. P. García-Escudero Márquez, «Voto parlamentario no presencial...», op. cit., pp. 90 y ss. Solo a partir de 1993 se aplicó estrictamente la limitación a una delegación por parlamentario. 
por supuestos relevantes, aplicándolo en primer lugar a los miembros del Gobierno (art. 154).

También la reforma de 2008 de la Constitución francesa (art. 25) ha introducido un supuesto de sustitución temporal para los ministros, que ya existía en Bélgica y algunos países nórdicos ${ }^{54}$.

\subsection{Voto a distancia}

En los países en que no se admite la delegación de voto y se afirma su carácter personal comienzan a aparecer formas de voto no presencial o a distancia, como la excepción prevista en el art. 70.A del Reglamento de la Cámara de Diputados de Grecia (voto por escrito que pueden emitir en Grecia los diputados en misión oficial en el extranjero) y la votación por escrito que puede desarrollarse en las comisiones del Bundestag alemán ${ }^{55}$.

Veremos que el voto a distancia ha sido también acogido por los Reglamentos de nuestras Cámaras; antes de proceder a su examen concluimos la revisión del panorama normativo con una referencia a las Constituciones históricas y al régimen vigente en los Parlamentos autonómicos.

\section{Derecho histórico}

No existen precedentes del art. 79.3 CE en nuestros textos constitucionales ${ }^{56}$. Tampoco existe previsión del voto por delegación ni de la sustitución temporal en los Reglamentos parlamentarios históricos. No obstante, algunos preceptos ofrecen interés en relación con el tema que nos ocupa ${ }^{57}$,

${ }^{54}$ Sobre la posibilidad de la sustitución temporal de parlamentarios en España y las reformas legales necesarias vid. M. A. PRESNO LINERA, «La sustitución temporal de los representantes políticos», en La sustitución temporal de los representantes políticos, Madrid, Centro de Estudios Políticos y Constitucionales, 2009, pp. 11 y ss.

55 Recogido bajo la rúbrica «Votación fuera de sesión» para casos de particular urgencia en las semanas en que no se celebre sesión plenaria, es escasamente utilizado.

${ }^{56}$ Un supuesto de sustitución de diputados por imposibilidad (aunque, obviamente, en términos conceptuales distintos a los aquí reseñados) encontramos en el art. 109 de la Constitución de 1812, según el cual: «Si la guerra o la ocupación de alguna parte del territorio de la monarquía por el enemigo impidieren que se presenten a tiempo todos o algunos de los diputados de una o más provincias, serán suplidos los que falten por los anteriores diputados de las respectivas provincias, sorteando entre sí hasta completar el número que les corresponda».

57 Puede verse una exposición in extenso, así como los preceptos relevantes, en P. GARCÍA-Escudero MÁrquez, «¿Voto no presencial o sustitución temporal de los parlamenta- 
como los relativos a la obligación de asistencia a las sesiones y a las excusas y licencias para ausentarse (siendo su concesión facultad del Pleno o de la Mesa), así como a la posibilidad de adherirse los ausentes (a partir de 1838) a las resoluciones adoptadas por la Cámara, si bien (como se especifica en los Reglamentos de 1931 y 1934) sin que ello afecte al acuerdo adoptado. En los Reglamentos de las Cortes de 1813 y 1821 y del Senado de 1838 (1842), 1847 (1866) y 1867, la obligación de asistencia se complementa con el deber de votar (excluyendo del mismo el Reglamento de 1813 a los diputados que no hubieren asistido a la discusión). En los Reglamentos de los Estamentos de Próceres y de Procuradores de 1834 se admite el derecho a manifestar la abstención (a decir un parlamentario que se abstiene de votar). La expresión derecho a votar aparece a partir del Reglamento de 1838 referido a los diputados que entren en el salón de sesiones antes de que se cierren las votaciones.

\section{Parlamentos autonómicos}

La preocupación por conseguir la igualdad en el trabajo de los parlamentarios y dar respuesta a las situaciones de ausencia por maternidad ha hallado reflejo en los Reglamentos autonómicos antes que en los del Congreso de los Diputados y el Senado ${ }^{58}$. La STC 179/1989 dejó claro que no es exigible que las instituciones legislativas de las Comunidades Autónomas deban adecuar su estructura, funcionamiento u organización a las correspondientes de las Cortes Generales, «ni que deban aplicarse a las Cámaras legislativas de las Comunidades Autónomas, en forma directa o supletoria, las normas constitucionales que regulen la organización y funcionamiento de las Cortes Generales, entre ellas el art. 79.2 CE», lo que, aplicado al 79.3 CE, ha permitido que distintos Parlamentos autonómicos hayan incluido en su Reglamento la posibilidad de delegación de voto en otro parlamentario ${ }^{59}$.

rios?», en L. López Guerra, J. L. García Ruiz y J. García Fernández (dirs.), Constitución y desarrollo político. Estudios en homenaje al profesor Jorge de Esteban, Valencia, Tirant lo Blanch, 2013, pp. 1057 y ss.

${ }^{58}$ Sobre la viabilidad constitucional de los mecanismos de ejercicio del mandato por el representante ausente que hemos examinado (voto no presencial, sustitución temporal y delegación de voto), vid. C. ORtega SANTIAGo, «El ejercicio del cargo representativo por el parlamentario ausente», en La sustitución temporal de los representantes políticos, Madrid, Centro de Estudios Políticos y Constitucionales, 2009, pp. 98 y ss.

59 Aunque esta interpretación no es unívoca. Sobre las dudas de admisibilidad —que 
Si bien en un primer momento la práctica totalidad de los Reglamentos autonómicos ${ }^{60}$ (con la excepción de los del Parlamento de Cataluña y del Parlamento Vasco) reproducían, en su regulación de las votaciones, el art. 79.2 RC (cuya primera parte, a su vez, procede del art. 79.3 CE) ${ }^{61}$, la situación normativa comienza a cambiar, con la admisión de la delegación en algunos Reglamentos y la incorporación a otros del voto no presencial.

Encontramos supuestos de delegación de voto en los Reglamentos de los Parlamentos de Cataluña ${ }^{62}$, País Vasco, Galicia, Andalucía, Navarra y Extremadura, generalmente en relación con la maternidad, paternidad y enfermedad grave o prolongada (en este caso, en Andalucía previo acuerdo del Pleno).

Los Reglamentos autonómicos, admitan o no la delegación, comienzan a incorporar el voto no presencial ${ }^{63}$ por causas similares a las citadas, regulando los supuestos y las votaciones a las que puede aplicarse con mayor o menor amplitud, así como la autorización por la Mesa y los sistemas técnicos que permiten la emisión del voto (Cataluña, Galicia, Andalucía, Can-

compartimos - y los problemas que plantea, vid. J. DE Miguel BÁRCENA, «La personalidad e indelegabilidad del voto y las reformas de los Reglamentos de los Parlamentos autonómicos», Revista Española de Derecho Constitucional, núm. 90 (2010), pp. 149-169.

${ }^{60}$ Así como algunos Estatutos de Autonomía, que reproducen el art. 79.3 CE, declarando la personalidad e indelegabilidad (los dos primeros que citamos califican al voto de no delegable en lugar de indelegable) del voto de los parlamentarios autonómicos: Asturias (art. 27.5), Cantabria (art. 12.3), Baleares (art. 44.2), La Rioja (art. 18.8) y Murcia (art. 26.5).

${ }^{61}$ El Reglamento del Parlamento de Canarias de 2009 (art. 91.5), tras la declaración de indelegabilidad del voto, salva la votación en comisiones por los diputados sustitutos de otros.

${ }_{62}$ Se han planteado en el Parlamento de Cataluña problemas en relación con el voto por delegación de diputados en el extranjero con orden de detención o en prisión preventiva. No vamos a detenernos en los incidentes, tan solo recordar el peligro que supone extender las excepciones (delegación de voto o voto no presencial) a la presencialidad que rige con carácter general como principio en las asambleas parlamentarias, las cuales, como tales excepciones, deben aplicarse restrictivamente. A medida que se amplían o estiran los supuestos de aplicación de estas excepciones a la inmediatez parlamentaria, los problemas se irán multiplicando, por tratarse, en definitiva, de un elemento extraño al sistema. Un ejemplo de hasta dónde puede vulnerarse el citado principio se halla en el intento de investidura sin la presencia del candidato a presidente.

${ }_{63}$ No podemos dejar de hacer un comentario sobre la terminología utilizada en algunas de estas normas, que podría inducir a confusión sobre la «laboralización» del cargo electo. Es evidente que la relación que los diputados mantienen con las instituciones parlamentarias no es de carácter laboral; deberían, en consecuencia, evitarse las referencias a veces deslizadas a «la baja»o «el permiso parental o maternal», que aparecía por otra parte también en un caso de alto cargo con una clara relación no laboral, en el Real Decreto 860/2008, de 19 de mayo, por el que se dispone la suplencia de la ministra de Defensa por el ministro de Interior en el despacho ordinario de los asuntos de su competencia «durante el tiempo en que se acoja al permiso de maternidad». 
tabria, La Rioja, Región de Murcia, Aragón, Canarias, Comunidad Valenciana, Extremadura, Illes Balears, Castilla y León).

\section{Voto telemático en el Congreso de los Diputados y en el Senado}

Entendiendo que el carácter personal del voto no exige la inmediatez en el tiempo ni la presencia, ambas Cámaras han incorporado también a sus Reglamentos la posibilidad del llamado voto telemático, esto es, mediante procedimientos electrónicos ${ }^{64}$. Estas reformas deben mantener la compatibilidad con el art. 79.3 CE, de forma que aquel se aplique solo con carácter excepcional, que no violente en exceso la concepción de la asamblea representativa como reunión de personas para deliberar (Cámara deliberante) en que se basa el principio democrático y las votaciones como regidas por el principio de unidad de acto. Y deben en todo caso habilitarse las garantías necesarias para asegurar que es el titular del mandato el que ejerce su derecho al voto libremente y que no se altera el sentido del mismo.

Por reforma de 21 de julio de 2011 se incorporó un nuevo apartado 2 al art. 82 del Reglamento del Congreso para permitir la emisión del voto por procedimiento telemático en los casos de embarazo, maternidad, paternidad o enfermedad grave en que, por impedir el desempeño de la función parlamentaria y atendidas las especiales circunstancias, se considere suficientemente justificado. La Mesa de la Cámara autoriza, a solicitud del diputado, la emisión de voto telemático con comprobación personal solo en las sesiones plenarias y para aquellas votaciones que, por no ser susceptibles de fragmentación o modificación, sea previsible el modo y el momento en que se llevarán a cabo ${ }^{65}$. El escrito de autorización de

${ }^{64}$ Conforme a la disposición final séptima de la Ley Orgánica 3/2007, de 22 de marzo, para la igualdad efectiva de mujeres y hombres: «A partir de la entrada en vigor de esta Ley, el Gobierno promoverá el acuerdo necesario para iniciar un proceso de modificación de la legislación vigente con el fin de posibilitar los permisos de maternidad y paternidad de las personas que ostenten un cargo electo». De las opciones posibles, el informe de la Subcomisión sobre las posibles modificaciones del régimen electoral general, creado en el seno de la comisión constitucional del Congreso (aprobado por la Comisión el 30 de junio de 2010, BOCG, Serie D, núm. 438, 4 de agosto de 2010), recomendaba el procedimiento por medios telemáticos, descartando la fórmula de sustitución por razones constitucionales.

${ }^{65}$ Con estas precisiones se pretende excluir aquellos puntos del orden del día cuya forma de votación puede cambiar durante el debate en Pleno, con posterioridad, por tanto, al momento de inicio y finalización del tiempo de emisión del voto telemático (que siempre es anterior al inicio de la sesión plenaria para la que se ha autorizado la emisión). 
la Mesa, que ha de ser motivado, precisará las votaciones y el periodo de tiempo en el que podrá emitirse el voto mediante este procedimiento, que habrá de ser verificado personalmente mediante el sistema que establezca la Mesa y obrará en poder de la Presidencia con carácter previo al inicio de la votación correspondiente ${ }^{66}$.

El desarrollo del procedimiento de voto telemático se rige por Resolución de la Mesa del Congreso de los Diputados de 21 de mayo de 2012. En la autorización se establecen los puntos concretos del orden del día del Pleno para el que se autoriza la votación mediante procedimiento telemático. En términos técnicos, la emisión del voto telemático se realiza a través de la intranet del Congreso de los Diputados y con comprobación telemática de la identidad del diputado autorizado mediante un certificado válido de firma digital. Tras la emisión del voto, el sentido del mismo es comprobado telefónicamente con el diputado autorizado por la Secretaría General del Congreso de los Diputados. Una vez realizada dicha comprobación, el voto telemático es trasladado a la Presidencia en orden a que pueda ser anunciado de forma acumulada con el resultado de las votaciones que se produzcan presencialmente. En los supuestos de empate, el voto telemático emitido se mantiene para las subsiguientes votaciones del mismo punto, siempre que se produzcan con carácter inmediato; en otro caso, la presidencia precisará si las subsiguientes votaciones pueden ser objeto de votación no presencial, lo que se comunicará al diputado solicitante, junto con los momentos de inicio y finalización del tiempo para ejercer el derecho de voto telemáticamente.

En las votaciones secretas por papeletas, el voto se imprimirá en una papeleta en la que constará el nombre o nombre de los candidatos elegidos, omitiéndose la identificación del diputado autorizado. La papeleta se introducirá por la presidencia en la urna.

Con el mismo objetivo de permitir la votación no presencial fue modificado el art. 92 del Reglamento del Senado mediante reforma de 21 de noviembre de 2013, cuyo apartado 3 ofrece una redacción similar a la del RC. El procedimiento de voto telemático se regula por la Resolución de la Mesa del Senado, de misma fecha, sobre desarrollo del procedimiento de votación telemática en las sesiones plenarias del Senado. Al existir en el Senado la modalidad de votación por bolas blancas y negras, se atribuye al

${ }^{66}$ Como se ha señalado, se añadió también en la misma Reforma un apartado 79.3 RC, para que se computen como presentes en la votación los miembros de la Cámara que, pese a estar ausentes, hayan sido expresamente autorizados por la Mesa para participar en la misma. Idéntica previsión contiene el nuevo apartado 3 del art. 93 RS. 
presidente el introducir en la bolsa la bola que corresponda al sentido del voto emitido, junto a las demás ya depositadas provenientes del voto presencial. Como peculiaridad técnicamente correcta, el art. 8.2 de la Resolución prohíbe la votación por asentimiento de los asuntos cuya votación telemática sea autorizada.

\section{Otras cuestiones relacionadas con la indelegabilidad del voto}

Algunas normas de los Reglamentos han sido cuestionadas en cuanto a su compatibilidad con la prohibición de delegación de voto contenida en el art. 79.3 CE.

Así, el art. 148.1 RC desarrolla el art. 75.2 CE estableciendo una presunción de delegación de la competencia legislativa plena en las comisiones permanentes para todos los proyectos y proposiciones de ley susceptibles de delegación por no versar sobre las materias excluidas por el art. 75.3 CE (reforma constitucional, cuestiones internacionales, leyes orgánicas y de bases y Presupuestos Generales del Estado) ${ }^{67}$. Más correctamente, el art. 130 RS exige acuerdo expreso del Pleno en cada caso para la delegación de la competencia legislativa plena respecto a un proyecto o proposición de ley.

También plantea dudas de constitucionalidad el voto ponderado, en virtud del cual al voto emitido por el representante de un grupo parlamentario se le otorga el valor correspondiente al número de miembros de dicho grupo en el Pleno de la Cámara ${ }^{68}$. Introducido primero en la práctica, la consagración del voto ponderado aparece en los Reglamentos en relación con las decisiones a adoptar por la Junta de Portavoces (art. 39.4 RC) y las comisiones de investigación (art. $52 \mathrm{RC})^{69}$ del Congreso de los Diputados y por las comisiones para el supuesto de empate en ambas Cámaras (arts. 88.2 RC y 100.4 RS, los dos últimos supuestos tras reformas de 16 de

${ }^{67}$ García Martínez, Recoder de Casso, Santaolalla o Punset (como yo misma) dudan de la conformidad de esta presunción de delegación con la indelegabilidad del voto constitucionalmente proclamada. Vid. P. García-Escudero MárQuez, «Normativa de desarrollo, artículo 75.2 y 3», en F. Garrido Falla (dir.), Comentarios a la Constitución, 3. ${ }^{a}$ ed., Madrid, Civitas, 2001, pp. 1285-1286.

${ }^{68}$ Sobre la problemática aplicación de la ponderación del voto del Grupo Mixto en ponencias y comisiones de investigación en la XII Legislatura puede verse, como se ha señalado, P. García-Escudero MárqueZ, «Un nuevo Parlamento fragmentado...», op. cit., pp. 79 y ss.

69 Además de para los acuerdos de la ponencia conjunta en la elaboración de los Estatutos de Autonomía tramitados conforme al art. 151 CE (art. 140.2 RC). 
junio de 1994 y 24 de octubre de 1995, respectivamente), y en el Senado, al regular la Comisión de Nombramientos (art. 185.2 RS, en el Congreso se establece por la Resolución de la Presidencia de 25 de mayo de 2000); en otras normas de desarrollo reglamentario, para la adopción de acuerdos por las ponencias (en el Senado, Norma interpretativa de 18 de noviembre de 1997; en el Congreso, Resolución de 18 de mayo de 2004, que modifica la de 23 de septiembre de 1986).

En lo que se refiere a la Junta de Portavoces y a las ponencias, al tratarse de órganos cuya composición no refleja la de la Cámara y cuyos acuerdos no sustituyen a los de esta — siendo de organización los de la primera y de propuesta a la comisión respectiva los emanados de las ponencias-, no parece que su regulación contradiga el art. 79.3 CE. Pero plantean más problemas los acuerdos de las comisiones, ordinariamente constituidas en proporción a la importancia numérica de los grupos parlamentarios en el Pleno, cuando en ocasiones, como en el caso de competencia legislativa delegada, expresan la voluntad de la Cámara. De ahí que, con anterioridad a la reforma de 1993, el art. 88.3 RC — hoy derogado- excluyera del recurso al voto ponderado en caso de empate los procedimientos legislativos en los que la comisión actuara con competencia legislativa plena, así como las mociones y proposiciones no de ley en comisión, supuestos en que intervendría el Pleno para dirimir el empate no resuelto en varias votaciones. Cabría defender, no obstante, que la ponderación de voto en comisión no es contraria a la indelegabilidad del voto, atendiendo a que las previsiones reglamentarias lo aplican solo como técnica no ya para dirimir un empate, sino para entender que este no se produce; también se ha considerado $^{70}$ que la nueva regulación del empate no es contraria a la personalidad e indelegabilidad del voto porque la garantía esencial de esa indelegabilidad está constituida por el requisito necesario para que el voto ponderado se pueda aplicar en comisión, esto es, que se haya producido el empate en la votación, y además que todos los miembros de la comisión y del mismo grupo parlamentario hayan votado en el mismo sentido.

En alguna ocasión ha sido objeto de debate público el ejercicio del voto de unos parlamentarios por otros. La Mesa del Senado, mediante acuerdo de 13 de marzo de $1991^{71}$, anuló por esta causa las votaciones correspondientes al proyecto de la que sería Ley 18/1991, de 6 de junio, del Impues-

70 C. Ortega Santiago, El mandato representativo de los diputados y senadores, Madrid, Congreso de los Diputados, 2005, p. 230.

${ }_{71}$ Vid. Diario de Sesiones del Pleno del Senado, de 16 de mayo de 1991, p. 3801. 
to sobre la Renta de las Personas Físicas, ordenando su repetición. Formuladas denuncias por falsedad y usurpación de funciones, la Sala Segunda del Tribunal Supremo acordó el archivo de las actuaciones (además de porque tal acto no pudo influir en la decisión y que esta se repitió con el mismo resultado mayoritario) sobre la base de que estas anomalías deben ser corregidas por las propias Cámaras en aplicación de sus normas reglamentarias internas (ATS de 21 de septiembre de 1992) ${ }^{72}$.

Más recientemente se ha producido el voto por un asistente siguiendo las instrucciones de una senadora con movilidad reducida que no se encontraba en su escaño. La Mesa del Senado, por Resolución de 13 de febrero de 2017 (que cita la STC 129/2006 — reseñada supra, apartado II.5— en relación con el carácter personal e indelegable del voto), acuerda anular el voto emitido y amonestar a la senadora «por promover la suplantación de su voto, apercibiéndola de que si dicha situación se repite en el futuro, se adoptarán las medidas sancionadoras oportunas».

En cualquier caso, parece claro que la terminante dicción del art. 79.3 CE excluye cualquier forma de delegación de voto conforme al modelo francés, ni siquiera como excepción, que — recordamos una vez más- en Francia (al igual que en Luxemburgo) es contemplada por la propia Constitución. Ya nos hemos referido a las regulaciones contenidas en los Reglamentos autonómicos y a la duda que suscitan incluso cuando ni el Estatuto de Autonomía ni el Reglamento proclaman la indelegabilidad del voto, sobre la base del carácter personal del mandato parlamentario y del principio de inmediatez característico de las asambleas, confirmado por las SSTC 19 y 45/2019.

\section{A MODO DE CONCLUSIÓN}

En los órganos colegiados, como son las asambleas parlamentarias, cobra particular importancia el respeto a las normas sobre adopción de acuerdos en la medida que son las que permiten imputar válidamente a la asamblea la voluntad de la mayoría. Hasta tal punto es así que son de las pocas normas de funcionamiento de las Cámaras incluidas en la Constitución.

\footnotetext{
72 Algún supuesto de voto por otros ha llegado al Tribunal Constitucional por la vía del amparo contra sanciones impuestas en Parlamentos autonómicos. Vid. supra STC 129/2006, apartado II.5.
} 
Apenas asumidas las novedades tecnológicas en la emisión de voto (votación electrónica), la introducción del voto no presencial y por delegación plantea cuestiones nuevas que no encajan en el tipo clásico de asamblea como reunión de hombres regida por la inmediatez espacial y temporal y en la que la deliberación precede a la decisión. No deben perderse de vista estos principios cuando se abordan aspectos procedimentales concretos, en apariencia intrascendentes pero que pueden llegar a hacer peligrar la esencia del Parlamento. 